\title{
A vision for transdisciplinarity in Future Earth: Perspectives from young researchers
}

Marta G. Rivera-Ferre, ${ }^{\text {* }}$ Laura Pereira, ${ }^{\mathrm{b}}$ Timothy Karpouzoglou, ${ }^{\mathrm{c}}$ Kimberly A. Nicholas, ${ }^{\mathrm{d}}$ Sheila Onzere, ${ }^{\mathrm{e}}$ Wilma Waterlander, ${ }^{\mathrm{f}}$ Fawzi Mahomoodally, ${ }^{\mathrm{g}}$ Anton Vrieling, ${ }^{\mathrm{h}}$ Fola D. Babalola, ${ }^{\mathrm{i}}$ Caroline C. Ummenhofer, ${ }^{\mathrm{j}}$ Atul Dogra, Aline de Conti, ${ }^{1}$ Susanne Baldermann, ${ }^{\mathrm{m}}$ Chijioke Evoh, ${ }^{\mathrm{n}}$ Silke Bollmohr ${ }^{\mathrm{o}}$

Submitted July 15, 2013 / Revised September 18, 2013 / Published online September 27, 2013

Citation: Rivera-Ferre, M. G., Pereira, L., Karpouzoglou, T., Nicholas, K. A., Onzere, S., Waterlander, W., Mahomoodally, F., Vrieling, A., Babalola, F. D., Ummenhofer, C. C., Dogra, A., de Conti, A., Baldermann, S., Evoh, C., \& Bollmohr, S. (2013). A vision for transdisciplinarity in Future Earth: Perspectives from young researchers. Journal of Agriculture, Food Systems, and Community Development, 3(4), 249-260.

http://dx.doi.org/10.5304/jafscd.2013.034.028

Copyright (C) 2013 by New Leaf Associates, Inc.

\section{Abstract}

Meeting the demand for food, energy, and water as world population increases is a major goal for the food systems of the future. These future challenges,

a* Corresponding author: Marta G. Rivera-Ferre, Department of Food and Environment. University of Vic. 08550-Vic

(Barcelona), Spain; martaguadalupe.rivera@uvic.cat

b Sustainability Science Program, Harvard University Kennedy School of Government, USA

c Stockholm Resilience Centre, Stockholm University, Sweden

d Lund University Centre for Sustainability Studies, Lund, Sweden

e University of Minnesota, Community Food Systems Program, USA

${ }_{\mathrm{f}}^{\mathrm{N}}$ ational Institute for Health Innovation, University of Auckland, New Zealand

$\mathrm{g}$ Department of Health Sciences, Faculty of Science, University of Mauritius, Mauritius

h University of Twente, Faculty of Geo-information Science and Earth Observation, The Netherlands which are complex, multiscalar, and cross-sectoral in nature, require a food systems approach that recognizes the socio-ecological and socio-technical dimensions of food (Ericksen, 2008; Ingram, 2011;

\footnotetext{
${ }^{i}$ Centre for Environmental Economics and Policy in Africa (CEEPA), University of Pretoria, South Africa

j Department of Physical Oceanography, Woods Hole Oceanographic Institution, Massachusetts USA

${ }^{k}$ International Center for Agricultural Research in the Dry Areas (ICARDA), India

${ }^{1}$ Department of Food and Experimental Nutrition, Faculty of Pharmaceutical Sciences, University of Sao Paulo, SP, Brazil, and Division of Biochemical Toxicology, National Center for Toxicological Research, Food and Drug Administration, USA

m Leibniz-Institute of Vegetable and Ornamental Crops Großbeeren/Erfurt e.V.; Institute of Nutritional Science, University of Potsdam, Germany

${ }^{n}$ Economic and Urban Policy Analysts (ECONUPA), USA

- Centre for Aquatic Research, University of Johannesburg, South Africa
} 
Rivera-Ferre, 2012). The United Nations' Future Earth Program aims to provide a new platform for consolidating the knowledge required for societies to transition to global sustainability (Future Earth Transition Team, 2012). In this paper, we explore how Future Earth could become a vehicle for inspiring the production of new research ideas and collaborations for sustainably transforming the future food system. We do this on the basis of a synthesis of views from 28 young (below 40 years old) food system scientists, representing five continents. Their expertise comes from disciplines including food engineering, agronomy, ecology, geography, psychology, public health, food politics, nutritional science, political science, sociology and sustainability science. This paper begins with an outline of the institutional framework of Future Earth and how it might support innovative transdisciplinary research on food systems, and the position of young scientists within this framework. Secondly, we outline the key insights expressed by the young scientists during the Food Futures Conference in Villa Vigoni, Italy, in April 2013, including the core research questions raised during the meeting as well as some of the challenges involved in realizing their research ambitions within their professional spheres.

\section{Keywords}

agri-food systems research, Future Earth, sustainability, trandisciplinarity

\section{Introduction}

In 2009, the UK's chief scientific advisor, Sir John Beddington, referred to the "perfect storm" of food, energy, and water crises that the world will be facing by 2050 . The expected population of around 9.3 billion by 2050 (United Nations, Department of Economic and Social Affairs, 2012), combined with increasing affluence, mean that the world will need to produce around 50 percent more food and energy, and that fresh water demand will rise by 30 percent (Beddington, 2009) if current consumption habits do not change. Meeting this demand to produce food, fuel, and fiber while maintaining or increasing social and environmental sustainability in the face of global environmental change (GEC), continuing population growth, changes in water availability, and competition between different land uses, is a major goal for the food systems of the future (Godfray et al., 2010; Misselhorn, Aggarwal, Ericksen, Gregory, Horn-Phathanothai, Ingram, \& Wiebe, 2012; Tilman, Christian, Jason, \& Belinda, 2011). These future challenges, which are complex, multiscalar, and cross-sectoral in nature, require a food systems approach that recognizes the socioecological and socio-technical dimensions of food (Ericksen, 2008; Ingram, 2011; Rivera-Ferre, 2012). This approach emphasizes the urgency of fostering innovative ways of thinking (Pretty, Toulmin, \& Williams, 2011; Rockström, Sachs, Öhman, \& Schmidt-Traub, 2013). That is, for radical change to succeed, innovation has to play a more central role in defining the research and policy agenda to determine food futures. The involvement of a broader set of actors is required, which entails rethinking how to transform our current academic institutions to support transdisciplinary research, including academic reward systems and acceptance of the value of new types of research (Mooney, Duraiappah, \& Larigauderie, 2013).

The Future Earth Program, a 10-year international research program launched in June 2012 at the United Nations (UN) Conference on Sustainable Development (Rio+20), aims to provide a new platform for consolidating the knowledge required for societies to transition to global sustainability (Future Earth Transition Team, 2012). In this paper, we explore how Future Earth could become a vehicle for inspiring the production of new research ideas and collaborations for sustainably transforming the future food system. We do this on the basis of a synthesis of views from 28 young (below 40 years old) food system scientists, representing five continents. Their expertise comes from disciplines including food engineering, agronomy, ecology, geography, psychology, public health, food politics, nutritional science, political science, sociology and sustainability science. In April 2013 these scientists came together under the auspices of the Future Earth program at the Food Futures Conference in Villa Vigoni, Italy, in order to seek bridges across their disciplines and to begin to think collectively about food futures. The aim of the meeting was to bring together fresh voices from different regions of the world to discuss the 
Figure 1. Schematic of the Conceptual Framework of Future Earth

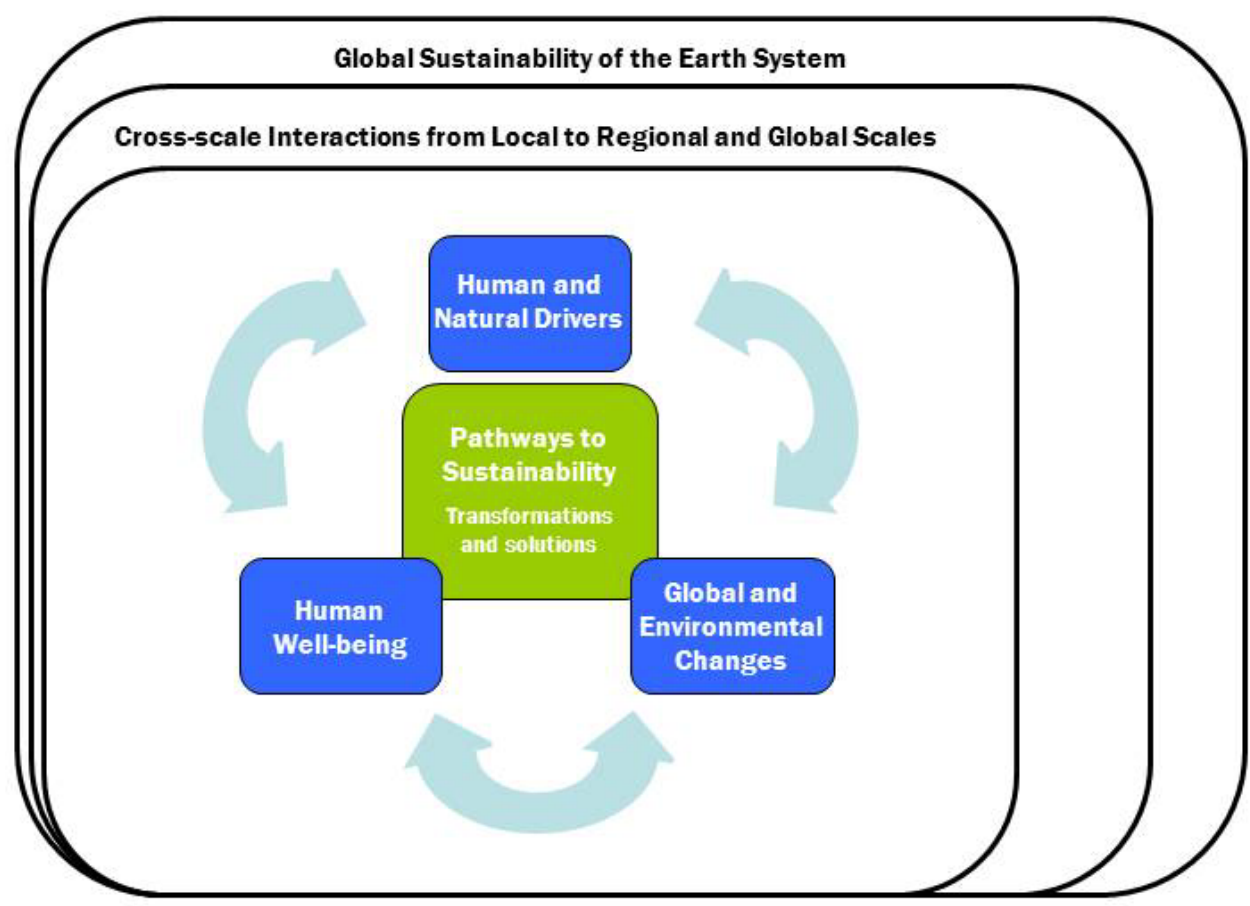

Adapted from Future Earth Transition Team (2013).

type of research and systemic change, including future research questions, that are needed to cultivate food sustainability. This paper begins with an outline of the institutional framework of Future Earth and how it might support innovative transdisciplinary research on food systems, and the position of young scientists within this framework. Secondly, we outline the key insights expressed by the young scientists during the Food Futures Conference, including the core research questions raised during the meeting as well as some of the challenges involved in realizing their research ambitions within their professional sphere.

We hope that the views of the scientists expressed in this paper can feed into the Future Earth program and activities in a way that can encourage greater involvement by young scientists in the process of formulating suitable research areas, questions, and pathways for sustainable food system research and practice.

\section{The Future Earth Program}

Since 2011 the International Council for Science (ICSU) and International Social Science Council
(ISSC) have been involved in many consultative processes to design a new international framework for conducting integrated science that will have relevance at both the national and global levels. This framework, called Future Earth, builds upon and integrates several pre-existing global environmental change programs: the World Climate Research Programme (WCRP), the International GeosphereBiosphere Programme (IGBP), the International Human Dimensions Programme (IHDP), DIVERSITAS (biodiversity conservation), and the Earth System Science Partnership (ESSP). Future Earth is supported by funding bodies such as the Belmont Forum and larger UN organizations including the United Nations Development Program, (UNDP), the United Nations Environmental Program (UNEP), the United Nations Educational, Scientific and Cultural Organization (UNESCO) and the United Nations University (UNU). ${ }^{1}$ It endeavors to expand significantly beyond the existing global networks and engage new institutions and researchers (Future Earth Transition Team, 2012).

The Future Earth vision is represented by a conceptual framework that describes an interconnected system in which both natural systems and human activities are driving changes in the regional and global environment affecting human well-being (figure 1). These interactions take place across a range of temporal and spatial scales. The framework emphasizes the challenge of under-

\footnotetext{
${ }^{1}$ http://www.icsu.org/future-earth/who
} 
standing and exploring avenues for human development within Earth system boundaries by fostering transdisciplinarity (Future Earth Transition Team, 2013). Future Earth's overarching framework therefore provides a sound basis for adopting a more holistic approach toward food system research that resonates with the socioecological systems approach inherent in the concept of food systems. This is reflected in the program's three thematic areas: Dynamic Planet, Global Development, and Transformation towards Sustainability. The framework aims to be innovative and open, particularly with regard to the importance of human values on sustainability, and explores what institutional, economic, social, technological and behavioral changes can enable effective steps toward global sustainability.

\section{Fostering Transdisciplinarity Within Future Earth}

Future Earth aspires to motivate scientists from all disciplines to work together, but also to broaden their networks beyond the research community in order to include other stakeholders and coproducers of knowledge. In food systems this could refer, for example, to the integration of farmers' traditional knowledge systems in current research, as well as to the engagement with agrofood companies, civil society, and policy-makers (e.g., McIntyre Herren, Wakhungu, \& Watson, 2009; United Nations Global Compact Office,, 2008). One important element to consider regarding the participation of different actors in science toward sustainability is to recognize the power of these actors in the participation process. In particular, power dynamics may affect the implementation and quality of participation, ranging from manipulation of local actors to self-mobilization of communities (Darnhofer, Gibbon, \& Dedieu, 2012; Pretty, 1995). As a result, two cross-cutting approaches within the Future Earth vision emerged as being crucially significant for advancing food system research and were discussed extensively during the Food Futures Conference: first, the codesign of research agendas with stakeholders (transdisciplinarity); and second, innovative communication models for high-impact research.

Against this backdrop, the Food Futures
Conference explored the dynamics of conducting and communicating transdisciplinary research on food system sustainability from scientists to a variety of stakeholders, including farmers, distributors, and policy-makers. What became clear, however, during the Food Futures Conference was that success will depend on much more than the novel institutional framework proposed by Future Earth. New pathways are needed where scientists inform, but do not drive, the research agenda singlehandedly. Essentially, the process of decisionmaking around food needs to become more socially and culturally sensitive, and political incentives and constraints need to be more clearly articulated within the Future Earth framework. The difficulties of mobilizing the humanities and social sciences to tackle what has traditionally been seen as a problem within the natural sciences requires fundamental reform of how these disciplines engage with each other (Palsson et al., 2013). There is a need for a more critical appreciation of what types of knowledge are required to create a sustainable food system; including multiple stakeholders with "expert" opinions will require a shift in the way that research is conducted in this field.

Along these lines, it was recognized that networking events for early-career researchers are clearly an important step in fostering a culture of inter- and transdisciplinary research. However, young scientists in the Food Futures Conference reported that in their respective institutions, transdisciplinarity is not always valued by their colleagues, nor does a transdisciplinary research profile necessarily encourage upward career mobility. In particular, they emphasized that the traditional incentives to publish in journals recognized by departments that grant tenure tend to focus on disciplinary and departmental approaches to publication, and that the pressure to publish as well as to perform teaching and service duties during the tenure process can discourage developing innovative research (Mooney et al., 2013).

This is a concern with serious implications for the Future Earth program. If the research questions outlined below are to be pursued by young scientists, then addressing these concerns is of the utmost importance, particularly in terms of the capacity of Future Earth to support initiatives that 
can foster greater recognition of transdisciplinary research within research institutions and universities. In particular, this includes encouraging young scientists to pursue these opportunities as they begin their careers. In addition to sponsoring networking events, these initiatives could include funding for working groups to write papers and proposals on interdisciplinary topics, support for travel to present interdisciplinary work at conferences or participate in research exchanges with other universities, and for professional development training in communication and leadership to advance young scientists' careers.

\section{Research Questions Raised During Food Futures}

A major goal of the Food Futures Conference was to bring young scientists together in a environment conducive to identifying key research questions in the area of food futures. This was accomplished through action research tools, such as World Café meetings and small- and large-group brainstorming and visioning sessions (figure 2 ). The young scientists took full advantage of this, and with a broad view of the entire food system they brought their many diverse research and personal backgrounds together to highlight and prioritize questions for addressing future challenges regarding the food system.

What follows is the set of questions that arose during the Food Futures Conference, which we present in comparison with a previously published synthesis of questions for global agriculture (Pretty et al., 2010). These questions were drawn from senior representatives of major agricultural organizations, professional scientific societies, and nongovernmental organizations. The submitted questions were sorted into 14 themes relating to different priority areas for research, such as climate change, use of fertilizers in agriculture, crop production systems and technologies, changing consumption patterns and health (Pretty et al., 2010). Table 1 in the appendix outlines the degree of overlap between the questions raised by young scientists through the participatory processes at the conference, and the research themes raised by the experts who contributed to the Pretty et al. (2010) article.

Before discussing the different implications of this comparison of research questions, it is important to consider the methodological differences that naturally resulted in different priorities. We had fewer than 600 questions. All our questions were developed on-site, and coding, sorting, and categorizing of the questions were done at the meeting. Our questions came out of sessions with different themes (Dynamic Planet, Global Development, and Transformation to Sustainability) and were elicited in a range of participatory and dynamic approaches (World Cafés, etc.). Pretty et al. (2010) solicited questions from experts who were not present in one place at one time, had more experts sort and categorize the questions who selected the five most important questions in each

\section{Figure 2. Examples of Diagram Outputs of the Action Research Methodologies Held at the Food Futures Conference in Villa Vigoni, Italy, in April 2013}
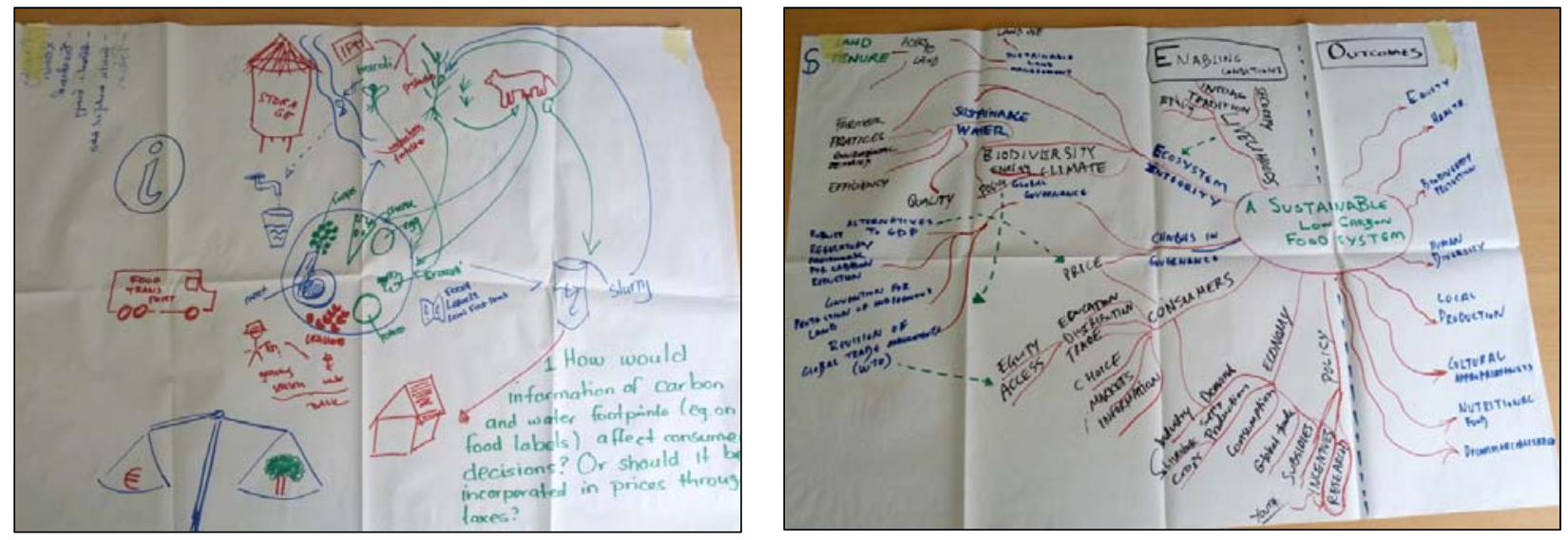
category, plus add a few more through discussion, to arrive at the agreed-upon number of 100 questions total. This process ensured a rough balance between the number of questions per theme. It is also important to consider that the two groups had different goals. We were explicitly encouraged to be bold, transformative, integrative in our thinking, and were selected for demonstrating this kind of thinking; the experts in Pretty et al. (2010) presumably selected questions more aligned with their disciplines.

In comparing our eight themes with the 14 from Pretty et al. (2010), several of them aligned directly (e.g., Institutions and Governance, Power Dynamics), some were clearly related (e.g., Information and Knowledge Sharing vs. Social Capital, Gender and Extension), and two of the themes did not align well with the existing framework (Metrics and Transformation) (table 1). It is particularly notable that young scientists did not come up with a theme focused on purely natural-science aspects, such as climate, soil, or biodiversity (columns a, b, and c), and that the majority of the themes explicitly included actors or stakeholders (e.g., farmers, power dynamics), reflecting a more integrated focus. This alignment also shows that all our research questions could be related to one or more of the themes from Pretty et al. (2010); more than half (24 out of 40) could be related to more than one theme, demonstrating the interdisciplinary nature of the questions from the young scientists. By far the theme most prevalent in our questions was governance (column k, table 1), with 17 related questions coming from every category, except Efficiency. The next most popular theme was consumption patterns and health (column $\mathrm{n}$ ), appearing in 11 of our questions.

Clearly, while the Pretty et al. (2010) research questions covered wider ground in terms of the themes they touched upon, the questions raised at the conference were much more cross-cutting in terms of the thematic areas they described. There were also gaps in our questions; questions relating to livestock and fishing systems and to pests and disease management were explicitly lacking, although as shown in table 1 in the appendix they can be related to broader general questions. The conference questions did highlight that there are some overarching concerns about doing transdisciplinary research on the food system that are not necessarily reflected in the Pretty et al. (2010) paper. The young scientists alluded more to the need to explore how to motivate people to create a culture of sustainability as a first priority. Furthermore, they articulated the need for new methodologies and metrics to address future challenges to conduct research that is relevant for individuals it concerns (e.g., farmers and consumers). This exercise shows that future research questions highlight the importance of being able to take up new perspectives, especially those that do not fit into established disciplinary paradigms. As table 1 indicates, there is clearly a hitherto unexplored space to incorporate previously underrepresented viewpoints on culture, personal and communal belief structures, norms, and behaviors.

\section{Conclusions}

The opportunity for gathering the questions raised by the young scientists at Villa Vigoni is the first step toward achieving a research agenda on food futures that could effectively meet the challenges that the food system faces. In facing the complexity of the theme itself, furthering understanding about issues regarding the future of food is possible only when experts from different areas are given a platform to communicate across disciplines and between different geographical regions.

This paper elucidates that merely setting out research questions and bringing researchers together is insufficient alone. Relationships between researchers in different disciplines from across the world need to be cultivated and allowed to develop continually in order to strengthen transdisciplinary engagement. This will require strengthening institutional support and providing greater incentives to encourage the next generation of scientists to tackle some of the world's most pressing food sustainability problems (e.g., food security, climate change, etc.). Future Earth can play a decisive role in realizing this vision by facilitating new types of processes for "risky" research and policy-making. The next step is to start addressing some of the barriers to transdisciplinarity that sit at the heart of an academic infrastructure that has its foundation in disciplines. 


\section{References}

Beddington, J. (2009). Food, energy, water and the climate: $A$ perfect storm of global events? London: Government Office for Science. Retrieved from http://www.bis.gov.uk/assets/bispartners/ goscience/docs/p/perfect-storm-paper.pdf

Darnhofer, I., Gibbon, D., \& Dedieu, B. (2012). Farming Systems Research: An approach to inquiry. Retrieved from http://www.wiso.boku.ac.at/fileadmin/ /H73/H733/pub/Ika/2012 FSR Inquiry.pdf

Ericksen, P. J. (2008). Conceptualizing food systems for global environmental change research. Global Environmental Change, 18(1), 234-245. http://dx.doi.org/10.1016/j.gloenvcha.2007.09.002

Future Earth Transition Team. (2012). Future Earth: Research for global sustainability. A framework document. Retrieved from the ICSU website: http://www.icsu.org/future-earth/mediacentre/relevant publications

Future Earth Transition Team. (2013). Draft initial design report. Retrieved from the ICSU website: http://www.icsu.org/future-earth/mediacentre/relevant publications

Godfray, H. C. J., Beddington, J. R., Crute, I. R., Haddad, L., Lawrence, D., Muir, J. F., Pretty, J., Robinson, S., Thomas, S. M., \& Toulmin, C. (2010). Food security: The challenge of feeding 9 billion people. Science, 327, 812-818. http://dx.doi.org/10.1126/science.1185383

Ingram, J. (2011). A food systems approach to researching food security and its interactions with global environmental change. Food Security, 3(4), 417-431. http://dx.doi.org/10.1007/s12571-0110149-9

McIntyre, B. D., Herren, H. R., Wakhungu, J., \& Watson, R. T. (Eds.). (2009). Agriculture at a crossroads: Synthesis report (Vol. 7 for the International Assessment of Agricultural Knowledge, Science and Technology for Development). Washington, D.C.: Island Press.

Misselhorn, A., Aggarwal, P., Ericksen, P., Gregory, P., Horn-Phathanothai, L., Ingram, J., \& Wiebe, K. (2012). A vision for attaining food security. Current Opinion in Environmental Sustainability, 4(1), 7-17. http://dx.doi.org/10.1016/i.cosust.2012.01.008

Mooney, H. A., Duraiappah, A., \& Larigauderie, A. (2013). Evolution of natural and social science interactions in global change research programs.
Proceedings of the National Academy of Sciences of the United States, 110(Supplement 1), 3665-3672. http://dx.doi.org/10.1073/pnas.1107484110

Palsson, G., Szersynski, B., Sörlin, S., Marks, J., Avril, B., Crumley, C.,...Weehuizer, R. (2013).

Reconceptualizing the 'Anthropos' in the Anthropocene: Integrating the social sciences and humanities in global environmental change research. Environmental Science and Policy, 28, 3-13. http://dx.doi.org/10.1016/j.envsci.2012.11.004

Pretty, J. N. (1995). Participatory learning for sustainable agriculture. World Development, 23(8), 1247-1263. http://dx.doi.org/10.1016/0305-750X(95)00046-F

Pretty, J., Sutherland W. J., Ashby, J., Auburn, J., Baulcombe, D., Bell, M., Bentley, J., . . . Pilgrim, S. (2010). The top 100 questions of importance to the future of global agriculture. International Journal of Agricultural Sustainability, 8(4), 219-236. http://dx.doi.org/10.3763/ijas.2010.0534

Pretty, J. Toulmin, C. \& Williams, S. (2011). Sustainable intensification in African agriculture. International Journal of Agricultural Sustainability, 9(1), 5-24. http://dx.doi.org/10.3763/ijas.2010.0583

Rivera-Ferre, M. G. (2012). Framing of agri-food research affects the analysis of food security: The critical role of the social sciences. International Journal of Sociology of Agriculture and Food, 19(2), 162-175.

Rockström, J., Sachs, J. D., Öhman, M. C., \& SchmidtTraub, G. (2013). Sustainable development and planetary boundaries: Background research paper. Retrieved from http://www.post2015hlp.org/wp-content/ uploads/2013/06/Rockstroem-Sachs-Oehman$\underline{\text { Schmidt-Traub Sustainable-Development-and- }}$ Planetary-Boundaries.pdf

Tilman, D., Balzer, C., Hill, J., \& Befort, B. L. (2011). Global food demand and the sustainable intensification of agriculture. Proceedings of the National Academy of Sciences of the United States, 108(50), 20260-20264. http://dx.doi.org/10.1073/pnas.1116437108

United Nations Global Compact Office. (2008). Food sustainability: A guide to private sector action. United Nations Global Compact Office. Retrieved from http://www.unglobalcompact.org/newsandevents/ news archives/2008 09 24d.html

United Nations, Department of Economic and Social Affairs. (2012). World population prospects: The 2012 revision. Retrieved from http://esa.un.org/wpp/ 
Table 1. Research Questions Identified by the Young Researchers at the Food Futures Conference and Grouped into Categories Compared with the 14 Themes Outlined by the Questions Raised by Pretty et al. (2010)

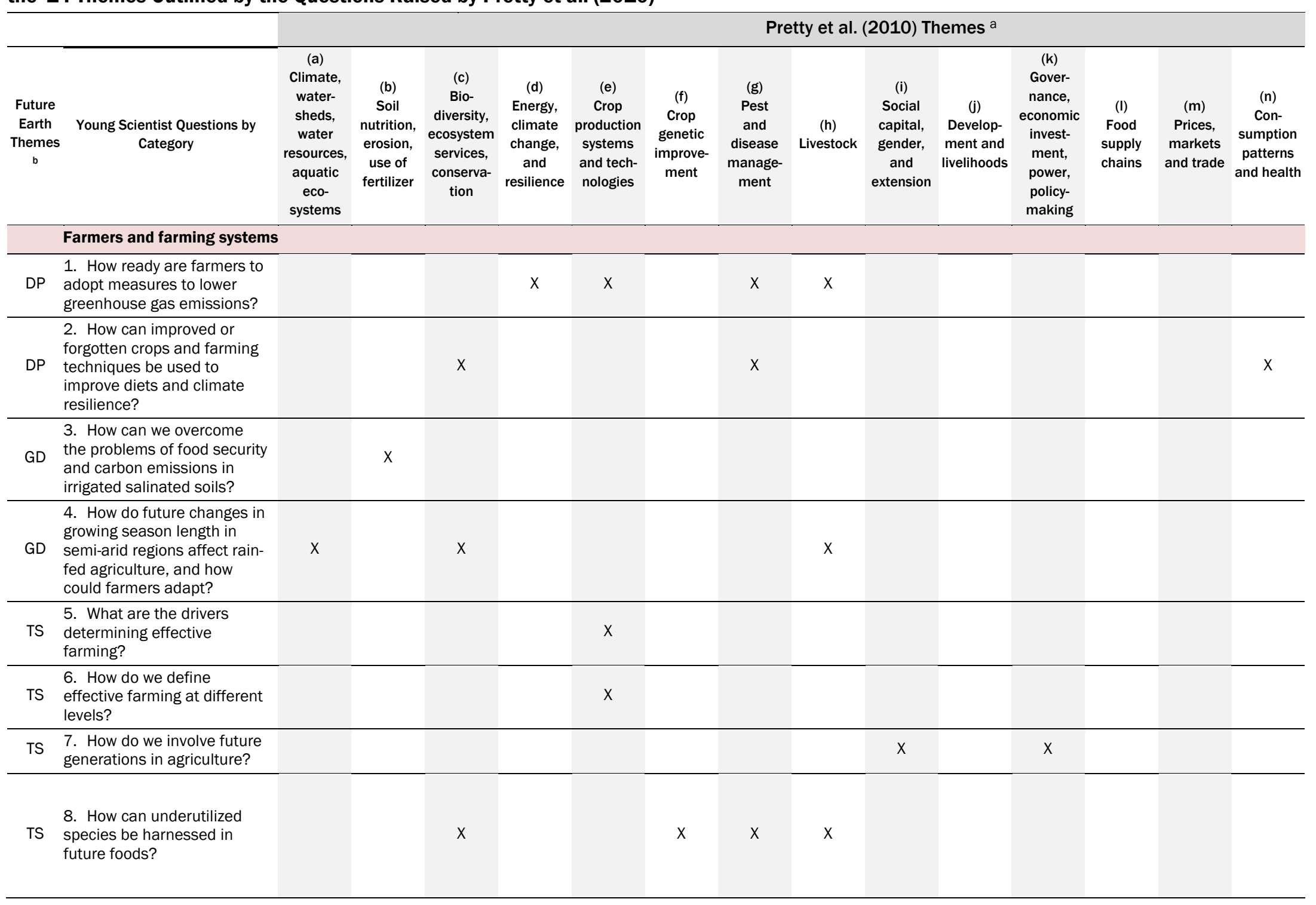


9. How can we improve

DP energy efficiency in the food system?

energy in food systems?

11. Where can we make the

DP biggest reductions in food waste?

12. Which tools are best for

GD efficient nutrient recycling strategies under different conditions?

Institutions and Governance

13. Why do we have so

much cheap junk food and

not enough nutritious food?

14. What institutions need to be designed to ensure

DP biodiversity conservation,

cultural preservation, and community resilience?

DP 15. What is the influence of trade on the food system?

16. What global trade rules

and conventions are needed

TS to promote local food

production and distribution

systems?

\begin{tabular}{l|l|}
\hline Information and Knowledge Sharing & $\mathrm{X}$ \\
\hline $\begin{array}{l}\text { 17. How do we integrate } \\
\text { local traditional knowledge } \\
\text { about climate change and } \\
\text { effectively transmit } \\
\text { sustainable scientific } \\
\text { information to farmers? }\end{array}$ & $\mathrm{X}$ \\
\hline $\begin{array}{l}\text { 18. How can food quality } \\
\text { and geographical indication } \\
\text { be used to promote more } \\
\text { sustainable food? }\end{array}$ & $\mathrm{X}$ \\
\hline $\begin{array}{l}\text { 19. What international alarm } \\
\text { systems can be put in place } \\
\text { to prevent starvation during } \\
\text { local food shortages? }\end{array}$ & $\mathrm{X}$ \\
\hline
\end{tabular}

d

$x$ 


x $\quad x$

resources?

21. How do we design

participatory research that

TS taps indigenous knowledge

to enhance its capacity to

produce enough healthy food

for well-being?

\section{Power Dynamics}

22. How can the public

health victory of tobacco

GD policy be a model for over-

coming powerful corporate

interests in food production?

23. How can we incorporate

GD power dynamics into a cross-

scale and cross-level analy-

sis of the food system?

24. How can we incorporate

TS power and inequalities in our

analysis of food?

25. How can we find cultur-

ally appropriate ways to

s empower communities to

utilize natural resources in

ways that increase

community resilience?

\section{Metrics}

26. What ecological, eco-

nomic, and social metrics

DP beyond GDP do we need to achieve a sustainable food system?

\section{Who is going to measure}

DP greenhouse gas emissions,

and how can it be done in a

cost-effective way?

28. What are new methods

to identify power trends

GD through interactions of

actors? Are new metrics

needed?

29. What tools can be used

TS to better inform consumer decisions?

$\mathrm{X}$

X

$\mathrm{x}$

X

$\mathrm{X}$ 
Linking Production and Consumption

30. What are the

DP mechanisms to harmonize

sustainable production with sustainable consumption?

31. What role can diets play

in reducing greenhouse

gases?

32. How can we develop and

DP implement technology to

improve food quality and

reduce carbon emissions?

33. How would environmen-

tal impact information, such

DP as carbon and water

footprints, and pricing policy

affect consumer decisions?

34. What mechanisms can

DP promote consumer

awareness of sustainable,

low-carbon food systems?

35. How can we make

GD people see the links between

individual consumption and

global impacts?

36. How can we reconnect

TS consumers to what and how

they eat?

Transformation

37. How can a healthy diet

be incorporated with food

GD security

environmental

sustainability?

38. What are the enablers of

transformations across

scales and levels in the food

system?

39. How do we transform

current practice to make the

food system "thrivable," and

safeguard the long-term

future with the resources we

have?

40. How can we improve the

TS multifunctionality of nationa

resources for resilience?

$\begin{array}{lll}x & x & x\end{array}$

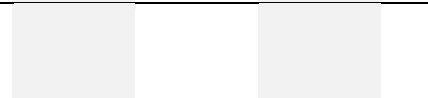

$x \quad x$

$x$

$x+x$

X

X

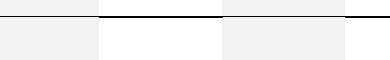

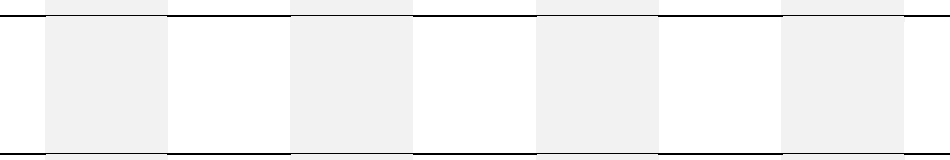

$x$

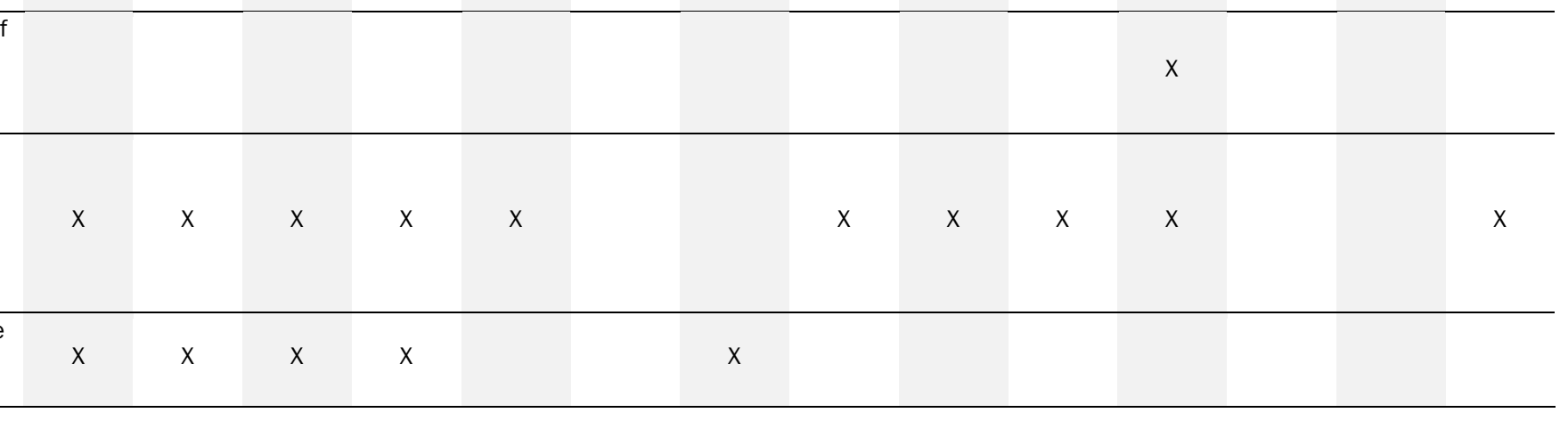


41. How do we change the

evaluation of junior scientists

to encourage the research

approach of Future Earth?

a Source of questions: Pretty, J., Sutherland W. J., Ashby, J., Auburn, J., Baulcombe, D., Bell, M., Bentley, J., . . Pilgrim, S. (2010). The top 100 questions of importance to the future of global agriculture. International Journal of Agricultural Sustainability, 8(4), 219-236.

${ }^{b} \mathrm{DP}=$ Dynamic Planet; GD = Global Development; $\mathrm{TS}$ = Transformation toward Sustainability 